\title{
The Accuracy Comparison Between Alvarado Score And Lrinec (Laboratory Risk Indicator For Necrotizing Fasciitis) Score In Diagnosing The Event Of Necrosis Appendicitis At H. Adam Malik General Hospital
}

\author{
Rizky Eka Putra, Adi Muradi Muhar, Edwin Saleh Siregar, Aznan Lelo \\ Department of Surgery, Faculty of Medicine, Universitas Sumatera Utara Haji Adam Malik General Hospital Medan - Indonesia \\ DOI: 10.29322/IJSRP.11.11.2021.p11928 \\ http://dx.doi.org/10.29322/IJSRP.11.11.2021.p11928
}

\begin{abstract}
Introduction The case of appendicitis is a surgical emergency that is very often encountered with the most common complications in the form of necrosis and perforation of appendicitis which is an abdominal emergency that requires immediate surgery. Difficulty in diagnosing results in increased morbidity, more complications, longer hospital stays and higher costs. There were 60 cases of acute appendicitis recorded at Haji Adam Malik Hospital Medan in 2009. There is no good scoring system as a predictor of necrotizing appendicitis cases, but based on several studies the use ofalvarado score and LRINEC (Laboratory risk indicator for necrotzing fasciitis) can be used to improve diagnostic procedures and determine the risk of developing necrotizing fasciitis. The researcher wanted to know the accuracy comparison between ALVARADO score and LRINEC score as a predictor of the incidence of necrotizing appendicitis at $\mathrm{H}$. Adam Malik Hospital, Medan.
\end{abstract}

Methods: Special design test research in the form of diagnostic tests from the results ALVARADO score and laboratory data. Sampling was carried out with the technique of consecutive sampling gbased on the inclusion and exclusion criteria of adult patients with complaints of abdominal pain and suspected appendicitis who had been treated at $\mathrm{H}$. Adam Malik Hospital in Medan since 2017.

Result: Positive predictive value $21.4 \%$ and negative predictive value $92.2 \%$ on ALVARADO score and score positive predictive value $16.6 \%$ and negative predictive value $84.3 \%$ on the LRINEC score with the cut value of ALVARADO used to determine necrotizing appendicitis is 9 while the cut of LRINEC value used to determine necrotizing appendicitis is 7 .

Conclussion: The use of ALVARADO and LRINEC scores cannot determine the incidence of necrotizing appendicitis.

Index Terms- ALVARADO score, LRINEC, necrotizing appendicitis

\section{INTRODUCTION}

$\mathrm{T}$ The first appendix is formed at the age of five months of pregnancy. The appendix is a continuation of the cecum, but the length of the appendix is not as fast as the rest of the colon, resulting in a worm-like structure (Minkes, 2012). The appendix produces $1-2 \mathrm{ml}$ of mucus per day. The mucus is normally drained into the lumen and then flows into the cecum. Inhibition of mucus flow in the mouth of the appendix seems to play a role in the pathogenesis of appendicitis (Sjamsuhidajat, 2004). Appendicitis is inflammation of the inside of the vermiform appendix that spreads to other parts (Craig, 2013).

In western countries, about $7 \%$ of the population experience appendicitis at some time in their lives (Obinna, 2011). In England it was reported that 40,000 patients per year were treated for appendicitis in Spain in 2003 it was reported that cases of appendicitis were 132.1 cases per 100,000 population where the proportion of perforated appendicitis was $12.1 \%$ and the proportion of negative appendicectomy operations was $4.3 \%$, while the mortality rate was $4.3 \%$. $0.38 \%$ (Aschraff, 2000). Men are more at risk of developing appendicitis than women with a ratio of 1.4:1. The peak incidence of appendicitis is at the age of 10-20 years (Saucier, et al., 2013). The amount of dietary fiber intake, lumen obstruction, and genetic factors are thought to play a role in the disease process. appendicitis begins with obstruction of the appendix lumen followed by infection (Lee, 2013). The basic pathophysiology of appendicitis is obstruction of the lumen of the appendix followed by infection (Obinna, et al. 2011). As obstruction develops, mucus secretion continues and increases intraluminal pressure. Then there is an overgrowth of bacteria. The mucus in the lumen turns into pus and the intraluminal pressure continues to rise. This causes distension of the appendix and characteristic visceral pain in the epigastric or periumbilical area because the appendix is innervated by the tenth thoracic nerve plexus (Ivan, 2013; Victor, et al., 2012). Complications of appendicitis include perforation, sepsis, shock, postoperative adhesions, surgical site infection, intestinal obstruction, intraabdominal/pelvic abscess, death (Craig and Minkes 2013). mucus secretion continues and increases intraluminal pressure. Then there is an overgrowth of bacteria. The mucus in the lumen turns into pus and the intraluminal pressure continues to rise. This causes distension of the appendix and characteristic visceral pain in the epigastric or periumbilical area because the appendix is innervated by the tenth thoracic nerve plexus (Ivan, 2013; Victor, et al., 2012). Complications of appendicitis include perforation, sepsis, shock, postoperative adhesions, surgical site infection, intestinal obstruction, intra-abdominal/pelvic abscess, death (Craig and Minkes 2013). mucus secretion continues and increases intraluminal pressure. Then there is an overgrowth of bacteria. The 
mucus in the lumen turns into pus and the intraluminal pressure continues to rise. This causes distension of the appendix and characteristic visceral pain in the epigastric or periumbilical area because the appendix is innervated by the tenth thoracic nerve plexus (Ivan, 2013; Victor, et al., 2012). Complications of appendicitis include perforation, sepsis, shock, postoperative adhesions, surgical site infection, intestinal obstruction, intraabdominal/pelvic abscess, death (Craig and Minkes 2013). This causes distension of the appendix and characteristic visceral pain in the epigastric or periumbilical area because the appendix is innervated by the tenth thoracic nerve plexus (Ivan, 2013; Victor, et al.,2012). Complications of appendicitis include perforation, sepsis, shock, postoperative adhesions, surgical site infection, intestinal obstruction, intra-abdominal/pelvic abscess, death (Craig and Minkes 2013). This causes distension of the appendix and characteristic visceral pain in the epigastric or periumbilical area because the appendix is innervated by the tenth thoracic nerve plexus (Ivan, 2013; Victor, et al., 2012). Histopathological examination is the gold standard for diagnosing appendicitis. Microscopically, neutrophilic infiltrates can be seen in the mucosal and muscularis layers up to the appendix lumen, or mucosal necrosis can be found up to an abscess (Santacrose, 2006). The Anatomical Pathology Department of H. Adam Malik Hospital uses the histopathological grouping of appendicitis into 2 groups, namely simple and complicated, what is said to be simple is acute appendicitis and what is said to be complicated is perforated appendicitis and gangrene.

In 1986, Alvarado created a scoring system consisting of 10 points which is also known by the abbreviation MANTRELS to diagnose acute appendicitis based on the patient's signs, symptoms and diagnostic tests with interpretation alvarado score in the form of a low probability of appendicitis (Alvarado Score 1-3), possible appendicitis (Alvarado Score 4-6), high probability of appendicitis (Alvarado Score 7-10). Changes in biochemistry and hematology innecrotizing fasciitis occurs early in the disease. LRINEC score can stratify patients into 3 risk categories, namely low (LRINEC score $<6$ ) with a risk of soft tissue necrosis $<50 \%$, moderate (LRINEC score 6-7) with a risk of soft tissue necrosis $50-75 \%$, and high (LRINEC score $>7$ ) with a risk of soft tissue necrosis $>75 \%$.

On the basis of the reasons mentioned above, the authors wanted to examine the comparison of the accuracy of the Alvarado score and the LRINEC score as a predictor of the incidence of necrotizing appendicitis at $\mathrm{H}$. Adam Malik Hospital, Medan.

\section{METHOD}

\section{Research Design and Sample}

This research is a special design test in the form of a diagnostic test to see a comparison of the accuracy of the results
Alvarado Score and has laboratory data to support diagnostics carried out by patients with complaints of abdominal pain and clinically diagnosed appendicitis who have been treated at $\mathrm{H}$. Adam Malik Hospital who have been treated since 2017. The sampling technique used non-probability sampling that is consecutive sampling where the sample must meet the inclusion criteria, namely, adult patients with complaints of abdominal pain who are diagnosed with suspected appendicitis and have histopathological data from surgery, and do not meet the exclusion criteria, namely, patients with damaged medical records. Furthermore, tabulation and statistical test results are carried outAlvarado Score and LRINEC with prediction of necrotizing appendicitis.

\section{Research Flow}

Data on adult patients with complaints of abdominal pain who according to the patient's medical record diagnosed with necrotizing appendicitis were collected and then the results were assessed. Alvarado Score and LRINEC. Patients with necrotizing appendicitis were then tabulated and statistical tests were performed. The data will be analyzed descriptively to see the frequency distribution of the research subjects based on the characteristics and types of appendicitis. Then it will be continued by calculating the value of sensitivity, specificity, positive predictive value and negative predictive value and then looking for cutoff from Alvarado Score and LRINEC Score using a 2x2 table.

\section{Research Ethics}

All research respondents first received an explanation orally about the purpose, workings, and benefits of the research. If you understand and agree to participate in the research, you are asked to sign a research permit. The research was conducted based on the ethics of health research, namely: carried out voluntarily after receiving an explanation of the research (objectives, methods and benefits) by signing a consent form (informed consent), the identity of the respondents and the data of the research results are kept confidential, and the research will be assessed by the Research Ethics Committee of the Faculty of Medicine, University of North Sumatra.

\section{RESULT}

In this study, 70 samples were obtained from sample calculations that met the inclusion criteria. The sample data were patients who had complaints of abdominal pain which, according to medical records, were diagnosed with necrotizing appendicitis at Haji Adam Malik Hospital, Medan. The description of the characteristics of the research sample is described as follows:

\section{Tabel 1. Age characteristics of appendicitis patients at H. Adam Malik Hospital Medan}

\begin{tabular}{ll}
\hline Number of patients & Median Age (Min-Max) \\
\hline 70 & $31(17-59)$ years old
\end{tabular}

This publication is licensed under Creative Commons Attribution CC BY 
In table 1 we found that from 70 patients, the mean age of the patients was 31.75 years. Where the age of the youngest patient is 17 years and the age of the oldest patient in this study is 59 years.

Tabel 2. Gender characteristics of appendicitis patients at H. Adam Malik Hospital Medan

\begin{tabular}{ll}
\hline Gender & Number of Patients $(\%)$ \\
\hline Man & 50 people $(71,4 \%)$ \\
Woman & 20 people $(28,6 \%)$ \\
\hline Total & 70 people $(100 \%)$ \\
\hline
\end{tabular}

Based on table 2, it was found that $71.4 \%$ male patients (50 people) and female patients $28.6 \%$ (20 people). In this study, the frequency of male sex is more than female.

Tabel 3. ALVARADO Score Level with necrotizing and non-necrotizing appendicitis cases at RSUP H. Adam Malik Medan

\begin{tabular}{llll}
\hline Score Level & Necrosis & Not Necrosis & Total \\
\hline High $(\geq 7)$ & $9(81,9 \%)$ & $33(55,9 \%)$ & 42 \\
Low $(<7)$ & $2(18,2 \%)$ & $26(44,1 \%)$ & 28 \\
\hline Total & & & \\
\hline
\end{tabular}

* The $\mathrm{p}$ value is statistically significant if $<0.05$

In table 3 of the 70 patients in this study, there were no necrosis cases with a low score of 26 people and a high score of 33 people. In the case of necrosis, the low score was 2 people and the high score was 9 people. The ALVARADO score showed a sensitivity of $81.8 \%$ and a specificity of $44.1 \%$ against necrotizing appendicitis. Obtained valuepositive predictive value $21.4 \%$ and negative predictive value $92.2 \%$.

Tabel 4. Groups of LRINEC scores in cases of necrotizing appendicitis and non-necrotizing appendicitis at RSUP H. Adam Malik Medan

\begin{tabular}{llll}
\hline Tingkat Skor & Nekrosis & Tidak Nekrosis & Total \\
\hline Resiko Tinggi $(>7)$ & $1(9,1 \%)$ & $5(8,5 \%)$ & 6 \\
\hline $\begin{array}{l}\text { Resiko Rendah- } \\
\text { Sedang( } \leq 7)\end{array}$ & $10(54,4 \%)$ & $54(79,7 \%)$ & 64 \\
\hline Total & $11(100 \%)$ & $59(100 \%)$ & 70
\end{tabular}

* $\mathrm{P}$ value is statistically significant if $<0.05$

Of the 70 patients in this study, there were 3 groups based on the LRIEC score with the incidence of appendicitis without necrosis, in which 54 people were in the Low-moderate Risk $(\leq 7)$ group, and 5 people in the High-Risk $(>7)$ group. While the incidence of appendicitis with necrosis in the Low Risk $(\leq 7)$ was 10 people, and the High Risk group $(>7)$ was 1 person. The LRINEC score showed a sensitivity of $9.09 \%$ and a specificity of $91.5 \%$ for the incidence of necrotizing appendicitis. Obtained valuepositive predictive value $16.6 \%$ and Negative predictive value $84.3 \%$. 


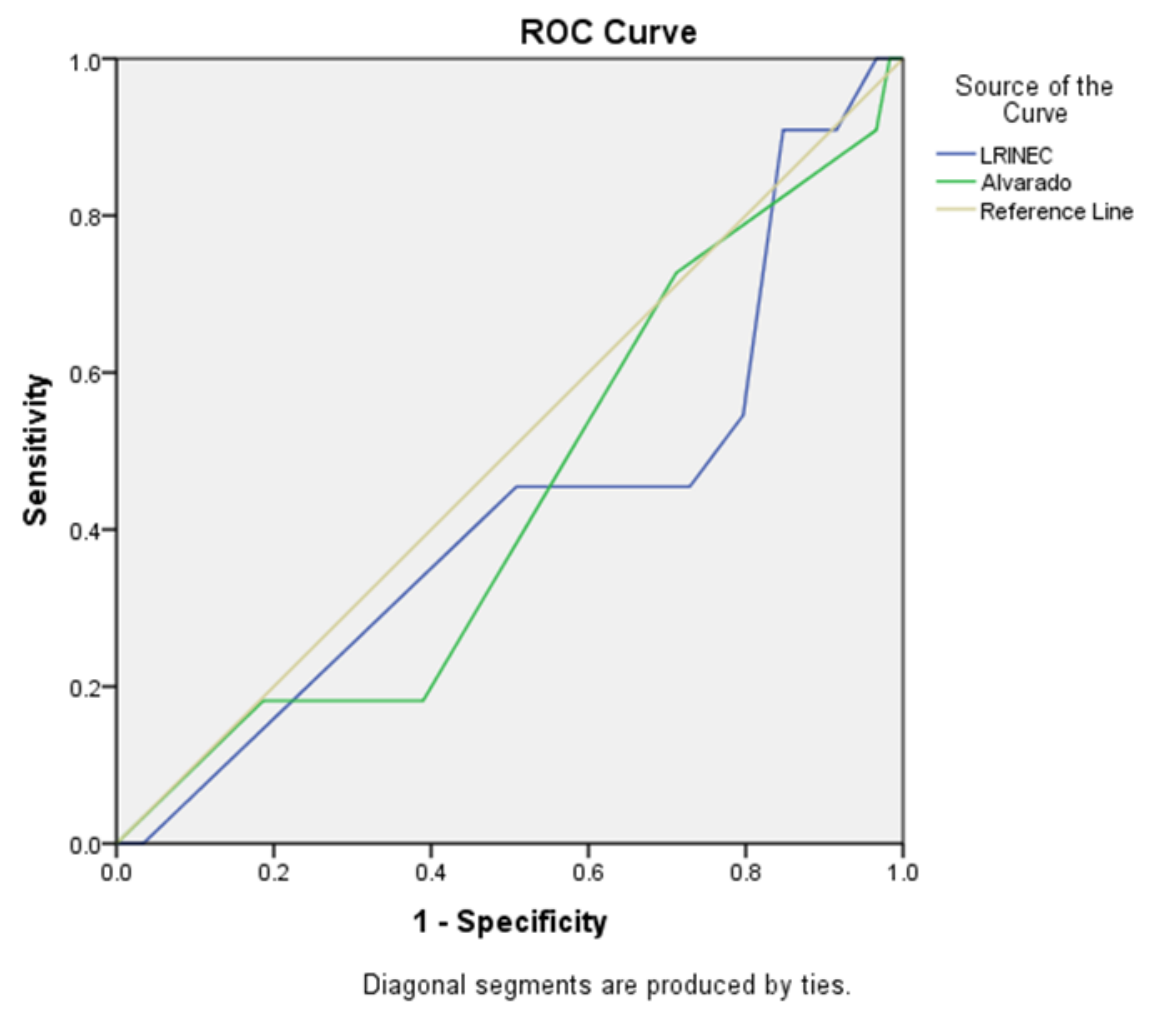

Tabel 5. ROC curve on ALVARADO and LRINEC scoring with necrotizing appendicitis.

\begin{tabular}{lccc}
\hline & Nilai & Sensitifitas & Spesifisitas \\
\hline Nilai Alvarado & 4 & 0 & 0 \\
& 6 & 0,182 & 0,186 \\
& 7 & 0,182 & 0,390 \\
& 8 & 0,727 & 0,712 \\
& 9 & 0,909 & 0,966 \\
& 10 & 1 & 0,983 \\
& 0 & 0 & 0,034 \\
& 1 & 0,455 & 0,508 \\
& 2 & 0,455 & 0,695 \\
& 4 & 0,455 & 0,729 \\
& 5 & 0,545 & 0,797 \\
& 7 & 0,909 & 0,847 \\
& 8 & 0,909 & 0,915 \\
& 9 & 1 & 0,966 \\
\end{tabular}


Tabel 6 Sensitivity and Specificity of ALVARADO and LRINEC scores in necrotizing appendicitis

* $\mathrm{P}$ value is statistically significant if $<0.05$

\begin{tabular}{lll}
\hline & Nilai Cut Of & Area dibawah kurva \\
\hline ALVARADO score & $\geq 9$ & 0,441 \\
Skor LRINEC & $\geq 7$ & \\
& & 0,423 \\
\end{tabular}

Based on the table above, the cut of ALVARADO vaue used to determine necrotizing appendicitis is $\geq 9$ while the cut of LRINEC value used to determine necrotizing appendicitis is $\geq 7$.

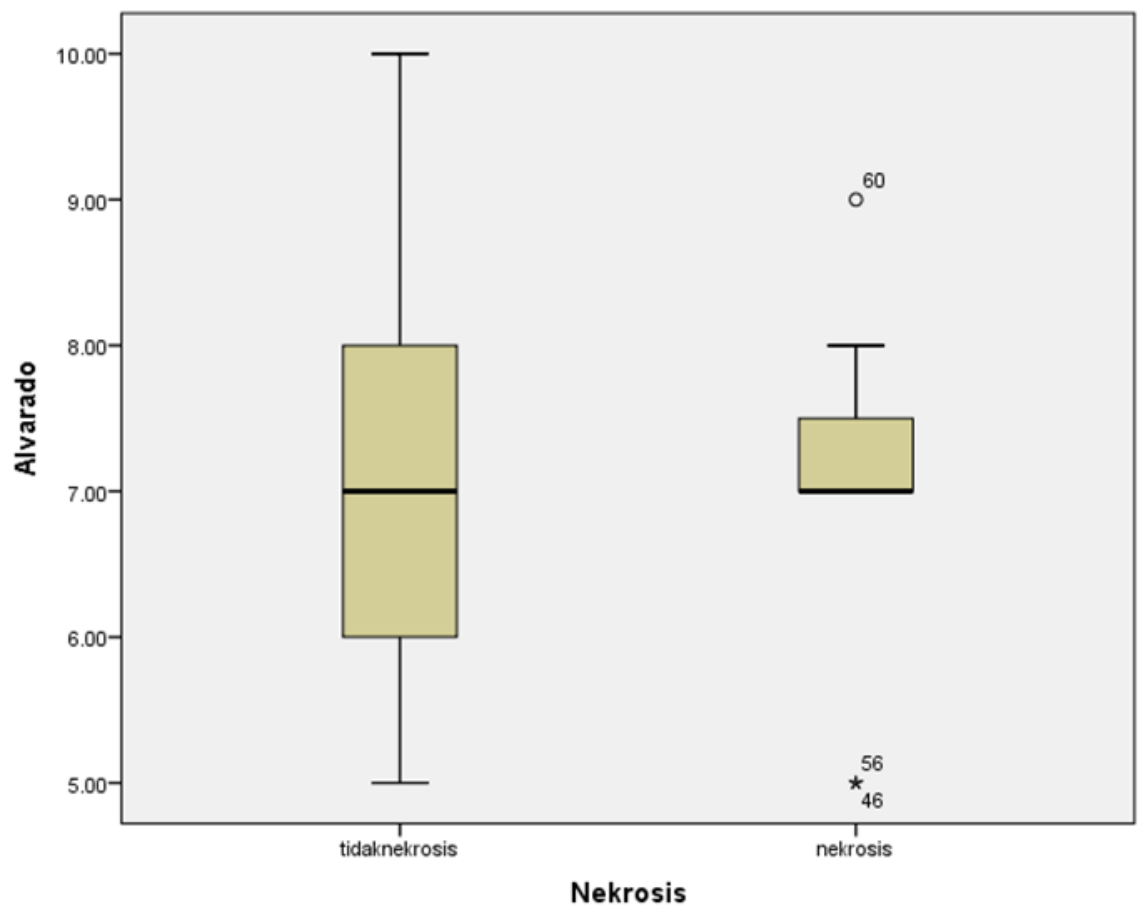




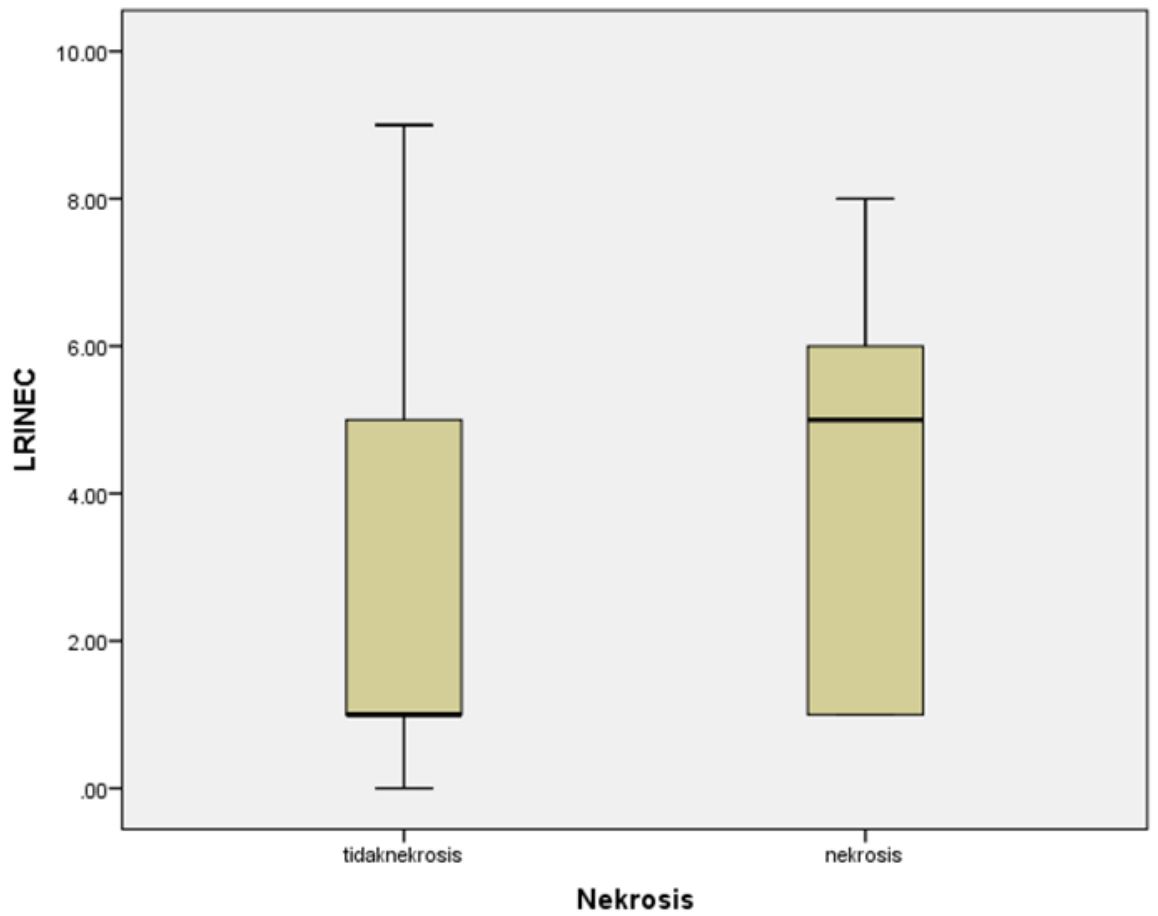

\section{DISCUSSION}

From the results of this study, there were 70 patients with appendicitis in adults, the mean age of the patient was 31.75 years. Where the age of the youngest patient is 17 years and the age of the oldest patient in this study is 59 years. It is estimated that as many as $6 \%$ to $7 \%$ of the general population will develop appendicitis during their lifetime, with the incidence peaking in the second decade of life (Sabiston, 2021). Age increase showed an increased risk due to the activity associated with the mucosa of the lymphoid tissue that composes the bulk of the vermiform appendix, it is believed that the incidence of acute appendicitis decreases after the third decade (Oguntola, Adeoti, Oyemolade, 2010). From the results of this study, there were 70 patients with appendicitis in adults, of which $50(71.4 \%)$ were male and 20 (28.6\%) were female. more than women. Appendicitis is a significant public health problem with a lifetime incidence of $8.6 \%$ in men and $6.7 \%$ in women, with the highest incidence occurring in the second and third decades of life (Schwartz, 2019). . A study in Thailand that examined appendicitis with necrosis in old age, found that male patients were more likely to experience appendicitis and necrosis with a significant p-value $(<0.005)$ (Sirikurnpiboon and Suparat Amornpornchareon.2015). There are several hypotheses regarding the high prevalence in males compared to females, appendiceal tissue has characteristics of lymphoid organs and there is more lymphoid tissue in young males. Lymphoid hyperplasia can be caused by an obstruction that occurs in the lumen of the appendix and can develop into appendicitis if the condition persists. There are several hypotheses regarding the high prevalence in males compared to females, appendiceal tissue has characteristics of lymphoid organs and there is more lymphoid tissue in young males. Lymphoid hyperplasia can be caused by an obstruction that occurs in the lumen of the appendix and can develop into appendicitis if the condition persists. There are several hypotheses regarding the high prevalence in males compared to females, appendiceal tissue has characteristics of lymphoid organs and there is more lymphoid tissue in young males. Lymphoid hyperplasia can be caused by an obstruction that occurs in the lumen of the appendix and can develop into appendicitis if the condition persists.

In this study, using alvarado scores obtained 70 patients in this study cases of non-necrosis with a moderate score of 26 people and a high score of 33 people. In the case of necrosis, the moderate score was 2 people and the high score was 9 people, with the $\mathrm{P}$ value in the Pearson chi-square hypothesis test of 0.108 which was not statistically significant. The Alvarado score is a commonly used diagnostic tool. When the score is high $(\geq 7)$, there is a strong indication for immediate surgery. When the score is low $(<4)$, a diagnosis of appendicitis is highly unlikely. Although the Alvarado score is used to establish the diagnosis of appendicitis, there are no studies that show the association of the Alvarado score with perforated appendicitis and also cannot measure the severity of the appendicitis. This is in accordance with this study which stated that there were no low alvarado scores who experienced necrosis and only 2 people (18.2\%) with moderate alvarado scores experienced necrosis. An Alvarado score of more than 7 has sensitivity and specificity for diagnosing appendicitis, but a high Alvarado score does not correlate with disease severity and cannot differentiate between perforated and acute appendicitis (Sirikurnpiboon and Amornpornchareon.2015). Until now the Alvarado score is the most commonly used score to diagnose acute appendicitis, although with advances in imaging modalities and the development of other scoring systems (Qamruddin, Ahmad, Mohamad, et al. An Alvarado score of more than 7 has sensitivity and specificity for diagnosing appendicitis, but a high Alvarado score does not correlate with disease severity and cannot differentiate between perforated and acute appendicitis (Sirikurnpiboon and Amornpornchareon.2015). Until now the 
Alvarado score is the most commonly used score to diagnose acute appendicitis, although with advances in imaging modalities and the development of other scoring systems (Qamruddin, Ahmad, Mohamad, et al. An Alvarado score of more than 7 has sensitivity and specificity for diagnosing appendicitis, but a high Alvarado score does not correlate with disease severity and cannot differentiate between perforated and acute appendicitis (Sirikurnpiboon and Amornpornchareon.2015). Until now the Alvarado score is the most commonly used score to diagnose acute appendicitis, although with advances in imaging modalities and the development of other scoring systems (Qamruddin, Ahmad, Mohamad, et al.Sukiman.2020). Some of the limitations of the Alvarado score include not being able to predict disease severity. There was no significant difference in the overall score between patients with and without necrosis. Second, patients with high risk scores, patients with moderate risk scores had the highest incidence of complicated appendicitis significantly among the three groups. Although the overall score cannot predict disease severity, individual analyzes reveal that fever, local right lower quadrant tenderness, and rebound tenderness are important clinical features that may indicate the presence of severe appendicitis. Based on the findings of this study, we recommend that signs of local tenderness and rebound tenderness should be properly assessed in any patient with suspected acute appendicitis. If resources allow, absolute neutrophil counts should also be measured in addition to simple leukocyte counts. To reduce the number of negative appendicectomy, radiological examination has been used quite often using ultrasound or CT-scan. In this study, the cut of Alvarado used to determine necrotizing appendicitis was 9, while the cut of LRINEC used to determine necrotizing appendicitis was 7. In the study of Saveria et al, although the Alvarado score was not specific in diagnosing acute appendicitis, the cut off was a score of $<5$ is sufficient to exclude acute appendicitis with a sensitivity of $99 \%$.

In this study, obtained from 70 patients in this study, there were 2 groups based on the LRIEC score with the incidence of appendicitis without necrosis where the Low- Medium Risk group $(\leq 7)$ were 54 people, Medium Risk and in the High Risk group $(>7)$ as many as 5 people. While the incidence of appendicitis with necrosis in the Low-Medium Risk $(\leq 7)$ was 10 people, and the High Risk group (>7) was 1 person.

The LRINEC score showed a sensitivity of $9.09 \%$ and a specificity of $91.5 \%$ for the incidence of necrotizing appendicitis. Obtained a positive predictive value of $16.6 \%$ and a negative predictive value of $84.3 \%$. Delay in early diagnosis can lead to an increase in the LRINEC score, this has been proven in the use of LRINEC in necrotizing fasciitis (Whong, Khin, Heng, et al. 2004). The LRIEC score has common biochemical laboratory parameters that can classify patients with soft tissue infections into necrotizing and non-necrotizing soft tissue infections. Patients with LRINEC scores $<6$ responded well to shorter hospital stays. Scores between 6 and 10 require aggressive, serial debridement and a longer hospital stay. The use of LRINEC scoring cannot be widely used for the management of emergency patients. One study stated several limitations of the LRINEC scoring system in patients with necrotizing fasciitis partly because of the small number of patients and the retrospective design. However, in this study the CRP value was not checked, because this was done after the patient was treated (Burner, Henderson, Burke. 2016). It has been suggested that the LRINEC score is capable of detecting early cases of patients with severe soft tissue infections. Wong et al. The importance of adopting an evidence-based approach to diagnosis using LRIEC in cases of appendicitis such as in cases of necrotising fasciitis to see the potential for early diagnosis, surgical intervention and reduction of morbidity and mortality (Bechar, Sepehripour, Hardwicke. 2017). In several studies, it was found that high serum CRP levels were associated with the incidence of complications of necrosis in appendicitis. For the ideal threshold for serum CRP level. In several studies, it was found that high serum CRP levels were associated with the incidence of complications of necrosis in appendicitis. (Fujiwara, Abe, Masatsugu, et all.2021).

\section{CONCLUSION}

Based on the results of the research that has been described previously, it can be concluded that:

1. Characteristics of patients in this study found appendicitis patients in adults with the mean age of the patient was 31.75 years with the youngest age 17 years and the age of the oldest patient being 59 years. Patients were more male than female, namely $71.4 \%$. ALVARADO cases of moderate scores scored 26 people and high scores as many as 33 people while in cases of necrosis the moderate score was 2 people and high scores were 9 people. There are 2 groups based on the LRIEC score with the incidence of appendicitis without necrosis in the low-moderate risk group as many as 54 people, the moderate risk group and 5 people in the high risk group, while the necrosis in the low-moderate risk group is 10 people and the high risk group is 1 person.

2. The use of ALVARADO and LRINEC scores cannot determine the incidence of necrotizing appendicitis.

\section{SUGGESTION}

Based on the results of the research that has been described previously, several suggestions can be made as follows:

1. For further research on the comparison of ALVARADO akurasi accuracy score and LRINEC score the incidence of perforated appendicitis should use a sample larger than the sample size of this study.

2. Look for variations in the age range that are not too far away.

Identify the constructs of a Journal - Essentially a journal consists of five major sections. The number of pages may vary depending upon the topic of research work but generally comprises up to 5 to 7 pages. These are:

1) Abstract

2) Introduction

3) Research Elaborations

4) Results or Finding

5) Conclusions

In Introduction you can mention the introduction about your research. 


\section{IDENTIFY, RESEARCH AND COLLECT IDEA}

It's the foremost preliminary step for proceeding with any research work writing. While doing this go through a complete thought process of your Journal subject and research for it's viability by following means:

1) Read already published work in the same field.

2) Goggling on the topic of your research work.

3) Attend conferences, workshops and symposiums on the same fields or on related counterparts.

4) Understand the scientific terms and jargon related to your research work.

\section{WRITE DOWN YOUR STUDIES AND FINDINGS}

Now it is the time to articulate the research work with ideas gathered in above steps by adopting any of below suitable approaches:

\section{A. Bits and Pieces together}

In this approach combine all your researched information in form of a journal or research paper. In this researcher can take the reference of already accomplished work as a starting building block of its paper.

Jump Start

This approach works the best in guidance of fellow researchers. In this the authors continuously receives or asks inputs from their fellows. It enriches the information pool of your paper with expert comments or up gradations. And the researcher feels confident about their work and takes a jump to start the paper writing.

\section{B. Use of Simulation software}

There are numbers of software available which can mimic the process involved in your research work and can produce the possible result. One of such type of software is Matlab. You can readily find Mfiles related to your research work on internet or in some cases these can require few modifications. Once these Mfiles are uploaded in software, you can get the simulated results of your paper and it easies the process of paper writing.

As by adopting the above practices all major constructs of a research paper can be written and together compiled to form a complete research ready for Peer review.

\section{GET PEER REVIEWED}

Here comes the most crucial step for your research publication. Ensure the drafted journal is critically reviewed by your peers or any subject matter experts. Always try to get maximum review comments even if you are well confident about your paper.

For peer review send you research paper in IJSRP format to editor@ijsrp.org.

\section{IMPROVEMENT AS PER REVIEWER COMMENTS}

Analyze and understand all the provided review comments thoroughly. Now make the required amendments in your paper. If you are not confident about any review comment, then don't forget to get clarity about that comment. And in some cases there could be chances where your paper receives number of critical remarks. In that cases don't get disheartened and try to improvise the maximum.

After submission IJSRP will send you reviewer comment within 10-15 days of submission and you can send us the updated paper within a week for publishing.

This completes the entire process required for widespread of research work on open front. Generally all International Journals are governed by an Intellectual body and they select the most suitable paper for publishing after a thorough analysis of submitted paper. Selected paper get published (online and printed) in their periodicals and get indexed by number of sources.

After the successful review and payment, IJSRP will publish your paper for the current edition. You can find the payment details at: http://ijsrp.org/online-publication-charge.html.

\section{CONCLUSION}

A conclusion section is not required. Although a conclusion may review the main points of the paper, do not replicate the abstract as the conclusion. A conclusion might elaborate on the importance of the work or suggest applications and extensions.

\section{APPENDIX}

Appendixes, if needed, appear before the acknowledgment.

\section{ACKNOWLEDGMENT}

The preferred spelling of the word "acknowledgment" in American English is without an "e" after the "g." Use the singular heading even if you have many acknowledgments.

\section{REFERENCES}

[1] G. O. Young, "Synthetic structure of industrial plastics (Book style with paper title and editor)," in Plastics, 2nd ed. vol. 3, J. Peters, Ed. New York: McGraw-Hill, 1964, pp. 15-64.

[2] W.-K. Chen, Linear Networks and Systems (Book style). Belmont, CA: Wadsworth, 1993, pp. 123-135.

[3] H. Poor, An Introduction to Signal Detection and Estimation. New York: Springer-Verlag, 1985, ch. 4.

[4] B. Smith, "An approach to graphs of linear forms (Unpublished work style)," unpublished.

[5] E. H. Miller, "A note on reflector arrays (Periodical style-Accepted for publication)," IEEE Trans. Antennas Propagat., to be published.

[6] J. Wang, "Fundamentals of erbium-doped fiber amplifiers arrays (Periodical style-Submitted for publication)," IEEE J. Quantum Electron., submitted for publication.

\section{AUTHORS}

First Author - Author name, qualifications, associated institute (if any) and email address.

Second Author - Author name, qualifications, associated institute (if any) and email address. 
Third Author - Author name, qualifications, associated institute (if any) and email address.
Correspondence Author - Author name, email address, alternate email address (if any), contact number. 